\title{
Diáspora africana, escravidão e a paisagem da cafeicultura no Vale do Paraíba oitocentista'
}

African Diaspora, Slavery and the Landscape of Coffee Plantation Areas in the 19th century Paraiba Valley

Rafael de Bivar Marquese Professor no Departamento de História da Universidade de São Paulo

\section{Resumo}

0 artigo analisa as estratégias de administração da paisagem e do trabalho adotadas nas fazendas escravistas de café do Vale do Paraíba ao longo do século XIX. Argumenta que a presença maciça da população africana escravizada, em um contexto local e global bastante turbulento, marcado pela competição entre diferentes produtores mundiais pelo controle do artigo e pelo acirramento da resistência escrava, levou à adoção, pelos senhores, de formas de administração da paisagem de suas fazendas que procuravam restringir a autonomia dos cativos no processo de trabalho.

\begin{abstract}
The article analyses the landscape and labor management devices adopted in the nineteenth century Paraiba Valley slave coffee plantations. It argues that the presence of an enormous mass of enslaved Africans in a quite turbulent local and global conjuncture framed by world competition between different coffee producers and increasingly slave resistance led planters to adopt measures of landscape administration which closely restricted slave autonomy in the labor process.
\end{abstract}

\section{Palavras-chave}

agricultura, escravidão, Brasil império, Rio de Janeiro, São Paulo

\section{Keywords}

agriculture, slavery, Brazilian Empire, Rio de Janeiro, São Paulo
Este artigo faz parte de um projeto coletivo intitulado "The World of the Plantation and the World the Plantations Made: the 'Great House Tradition" in the American Landscape", que conta com uma Collaborative Research Grant da Getty Foundation, e que se articula também a uma outra pesquisa financiada pelo CNPq. 
É errado afirmar que existem paisagens feitas à medida do homem e outras que não o são. Toda paisagem do mundo é feita à medida do homem, pois o homem sempre servirá de módulo a tudo que concerne à Terra. 0 que resta saber é para que homens foi feita semelhante paisagem - para que olhos, para que sonhos, para que empenhos

Alejo Carpentier, A Grande Savana: mundo do Gênesis (1947)

Em janeiro de 1822, ao regressar à cidade do Rio de Janeiro após ter explorado, em diversas viagens científicas, territórios do sul e do centro-sul do Brasil, o naturalista francês Auguste de Saint-Hilaire constatara que parte de sua coleção coletada nas províncias do Rio de Janeiro e de Minas Gerais havia se estragado. Aborrecido, porém resignado, resolveu empreender sua última viagem antes de regressar à França. Assim, entre os meses de janeiro e maio de 1822, voltou a atravessar as trilhas de mulas que cortavam a Serra do Mar, o vale do rio Paraiba do Sul e a Serra da Mantiqueira em direção ao sul de Minas, tendo a oportunidade de percorrer o "Caminho do Comércio", aberto há poucos anos com o objetivo de articular a então sede do Império português à zona de produção de mantimentos das terras altas da Mantiqueira.

Afora o vaivém de tropeiros e dos pousos ao longo do caminho, dois outros pontos mereceram o registro do naturalista já enfastiado. Em dois de fevereiro, após vencer os primeiros contrafortes da Serra do Mar, escreveu: "o terreno continua montanhoso e coberto de florestas virgens". No dia seguinte, às margens do rio Paraiba: "nada de notável na estrada. 0 terreno continua montanhoso e coberto de mata virgem". Quatro de fevereiro, após cruzar o rio: "terreno sempre montanhoso e coberto de florestas". Dia cinco, nas proximidades do futuro município de Valença, "continuam as montanhas e florestas. Um pouco antes da chegada à Aldeia, avista-se do pico de elevada montanha imensa extensão de terreno, notando-se de todos os lados montanhas cobertas de mato". Entre este ponto e o registro do Rio Preto, na fronteira com Minas Gerais, seis de fevereiro: "para chegar a Rio Preto, atravessa-se sempre terreno montanhoso e coberto de mato virgem, e quando sobre algum cume elevado se pode avistar grande extensão de SAINT HILAIRE, Auguste de. Segunda Viagem do Rio de Janeiro a Minas Gerais e a São Paulo (1822). (trad.port.) São Paulo: Edusp - Belo Horizonte: Itatiaia, 1974. p.20-24.

LAËRNE, C.F.van Delden. Brazil and Java. Report on Coffee-Culture in America, Asia, and Africa. Londres-Haia: Martinus Nijhoff, 1885. p.282283.

\section{terras, só se notam florestas e montanhas" 2.}

Sessenta anos depois, cobrindo a mesma região no sentido lesteoeste, agora em confortáveis vagões ferroviários e não mais no lombo de mulas, o agrônomo holandês C.F. van Delden Laërne viu uma paisagem completamente distinta. A monotonia continuava a dar o tom, só que em outro diapasão. "A porção do Vale do Paraiba que engloba os distritos de Barra Mansa, Piraí, Vassouras, Valença e Paraiba do Sul", anotou,

\footnotetext{
é considerada no Brasil como já exaurida pela metade. Uma viagem através dessa região é a coisa mais triste que se pode imaginar em um país tropical. Por longas horas o trem avança pelos morros pelados, guarnecidos por gigantescos vassourais cinzas, deploráveis reliquias de plantações de café outrora tão esplêndidas que, pode-se dizer, produziam ouro ${ }^{3}$.
}

A última frase fornece a chave para entender o que ocorreu na região. Quando Saint-Hilaire a cruzou, em 1822, a cafeicultura brasileira iniciava o arranque que logo isolaria o Brasil como o maior produtor do artigo no mercado mundial. 0 vale do rio Paraiba do Sul, ou simplesmente Vale do Paraiba, compreendendo terras das províncias de São Paulo, Rio de Janeiro e Minas Gerais, passou por uma completa alteração no curso de duas gera- 
Cf. FlOREnTINO, Manolo Garcia. Em Costas Negras. Uma História do Tráfico Atlântico de Escravos entre a África e o Rio de Janeiro (séculos XVIII e XIX). Rio de Janeiro: Arquivo Nacional, 1995. p.59.

5

Cf. MATTOS, Ilmar Rohloff de. O tempo saquarema. A formação do Estado Imperial. São Paulo: INL/Hucitec, 1987; PARRON, Tâmis Peixoto. A política do tráfico negreiro no Império do Brasil, 1826 a 1850. Relatório Final de Iniciação Científica Fapesp. São Paulo: DH/ FFLCH/USP, 2006. p.53-115; YOUSSEF, Alain el. Opinião pública e escravidão: os periódicos do Império do Brasil na década de 1830. Relatório Final de Iniciação Científica Fapesp. São Paulo: DH/FFLCH/USP, 2007. p.70.

Cf. SALLES, Ricardo Henrique. E o Vale era o escravo. Vassouras - século XIX. Senhores e escravos no coração do Império. Rio de Janeiro: Civilização Brasileira, 2008; MARQUESE, Rafael; TOMICH, Dale. 0 Vale do Paraiba escravista e a formação do mercado mundial do café no século XIX. In: SALLES, R.; GRINBERG, K. (org.) O Brasil Império (1808-1889). Volume 2 (18311871). Rio de Janeiro: Civilização Brasileira (no prelo)

7

SLENES, Robert W. 'Malungo, ngoma vem!' África coberta e descoberta no Brasil. In: Araújo, E. (org.) Negro de corpo e alma. Mostra do Redescobrimento. Brasil 500 anos. São Paulo: Fundação Bienal de São Paulo, 2000. p.214.

Cf. GOMES, Flávio dos Santos. Histórias de quilombolas. Mocambos e comunidades de senzalas no Rio de Janeiro, século XIX. (Edição revista e ampliada) São Paulo: Companhia das Letras, 2006. p.163-78; SALLES, Ricardo Henrique. Op.Cit.; MORENO, Breno Aparecido Servidone. Café e escravidão no Caminho Novo da Piedade: a estrutura de posse de escravos em Bananal (1830-1888). Relatório Parcial de Iniciação Científica/FAPESP. São Paulo: DH/ FFLCH/USP, 2008; FRAGOSO, João Luis Ribeiro. Comerciantes, fazendeiros e formas de acumulação em uma economia escravista-colonial: Rio de Janeiro, 1790-1888. Tese (Doutorado em História). Niterói: ICHF-UFF, 1990. p.363-365

Cf. CARNEY, Judith A. Black Rice. The African Origins of Rice Cultivation in the Americas. Cambridge, Mass.: Harvard University Press, 2001. ções: relativamente desocupado em 1800, cinqüenta anos depois adquiriria o caráter de típica região escravista de plantation, mobilizando, para tanto, vastas quantidades de trabalhadores cativos para a exploração de seus recursos naturais.

Com efeito, o processo de ocupação do Vale do Paraíba guardou estreita conexão com o tráfico negreiro transatlântico. 0 enorme volume do tráfico entre 1811 e 1830, quando desembarcaram nos portos do centro-sul do Império do Brasil cerca de 450.000 africanos escravizados ${ }^{4}$, forneceu a força de trabalho inicial para as primeiras fazendas de café do Vale. Nos três anos que se seguiram à aprovação da lei de 7 de novembro de 1831, o tráfico - agora ilegal - se tornou como que residual, haja vista que o decreto regencial fora lido pelos contemporâneos como uma medida que seria efetivamente cumprida. A prática sistemática do tráfico ilegal, em números equivalentes aos da década de 1820, foi retomada somente após 1835, em grande parte como resultado das ações dos cafeicultores e de seus representantes, que passaram a demandar nos espaços de discussão pública do Império a anulação da lei de 1831, no que operaram em estreita articulação com o grupo político do Regresso que reconfigurou as bases institucionais do Estado brasileiro entre 1837 e $1841^{5}$. Entre 1835 e 1850, na medida que aportavam no centro-sul cerca de 315.000 africanos ilegalmente escravizados, expandiam-se serra acima as grandes fazendas cafeeiras com mais de cinqüenta cativos cada, responsáveis pelo grosso da produção brasileira ao longo do século XIX6.

Quando se encerrou de forma definitiva o tráfico negreiro transatlântico, a demografia dos principais municípios do médio Vale do Paraiba, coração da cafeicultura brasileira, bem demonstrava a correlação estreita entre uma atividade e outra. Valendo-se dos relatórios dos presidentes da província do Rio de Janeiro, Robert Slenes calculou que, no município de Vassouras no ano de 1850, "72 \% dos escravos, $60 \%$ do total de pretos e pardos e $49 \%$ de toda a população eram africanos" 7 . Estes dados são corroborados por pesquisas que quantificaram a presença de escravos africanos nos inventários abertos em Vassouras, Paraiba do Sul e Bananal nas décadas de 1830 e 1840 . Seus autores indicaram a clara presença de uma típica demografia de plantation, isto é, a concentração da escravaria em grandes unidades rurais, com amplo predomínio masculino e força de trabalho composta por mão-de-obra em idade produtiva ideal8.

Tais informações colocam, por si, o seguinte problema: qual o papel dos africanos escravizados na conformação da paisagem cafeeira do Vale do Paraiba? Para além da óbvia constatação de que foram os braços dos africanos e de seus descendentes que derrubaram as matas, plantaram os arbustos, colheram e beneficiaram suas safras e ergueram as imponentes sedes das fazendas, parte das quais ainda de pé, a pergunta remete a um ponto que vem chamando a atenção de especialistas nos últimos anos, qual seja, a agência africana na configuração da paisagem do Novo Mundo. Um dos trabalhos mais relevantes neste campo certamente é o da geógrafa Judith Carney. Ao estudar a implantação da rizicultura nas Américas, em especial nas terras baixas da Carolina do Sul, a autora demonstrou como os saberes originalmente elaborados na costa da África ocidental e trazidos nos navios negreiros pelos próprios africanos escravizados foram decisivos para o sucesso da atividade no Novo Mundo ${ }^{9}$. Com base nesta descoberta, Carney propôs mais recentemente, com o também geógrafo Robert Voeks, um amplo programa de pesquisas para examinar as marcas da diáspora 
10

Cf. CARNEY, Judith A.; VOEKS, Robert. Landscape legacies of the African diaspora in Brazil. Progress in Human Geograph,.vol. 27, n.2, p.139-152, 2003, p.141.

11

Cf. ECCARDI, Fulvio; SANDALJ, Vincenzo. O café: ambientes e diversidade. (trad.port.) Rio de Janeiro: Casa da Palavra, 2003. p.21.

\section{2}

KAYE, Harvey J. E.P.Thompson, the British Marxist Historical Tradition and the Contemporary Crisis. In: KAYE, H.; McCLELLAND, K. (org.). E.P.Thompson. Critical Perspectives. Philadelphia: Temple University Press, 1990. p.260.

13

Cf. MARQUESE, Rafael de Bivar. Moradia escrava na era do tráfico ilegal: senzalas rurais no Brasil e em Cuba no século XIX. Anais do Museu Paulista. História e Cultura Matéria,. Nova Série, vol. 13, n.2, p.165-188, julho-dezembro de 2005.

\section{4}

Cf. TUCHSCHERER, Michel. Coffee in the Red Sea Area from the Sixteenth to the Nineteenth Century. In: CLARENCE-SMITH, W.G.; TOPIK, S. (org.). The Global Coffee Economy in Africa, Asia, and Latin América, 1500-1989. Cambridge: Cambridge University Press, 2003.

\section{5}

Cf. MARIA RODRIGO, Vicente; BOLOIX, Pablo. Informe de la comisión nombrada por la Real Sociedad, para examinar un escrito anonimo, sobre un nuevo método para el cultivo y beneficio del café. Memórias de la Real Sociedad Económica de la Habana. N.5, p.165-168, maio de 1817; CALDEIRA, Antonio da Silveira. Memória sobre um novo método de preparar o café. Rio de Janeiro: Typ.Universal de Laemmert, 1843, p.1011; TUCHSCHERER, Michel. Op.Cit., p.54.

16

Cf. CAMPBELL, Gwyn. The Origins and Development of Coffee Production in Réunion and Madagascar, 1711-1972. In: CLARENCESMITH, W.G.; TOPIK, S. (org.). The Global Coffee Economy in Africa, Asia, and Latin América, 1500-1989. Cambridge: Cambridge University Press, 2003. p.69. africana na paisagem brasileira, notadamente o legado dos africanos na manipulação de "recursos alimentares para a subsistência, sobrevivência, resistência e identidade" próprias ${ }^{10}$. Esses dois geógrafos lembram, afora o caso do arroz, uma ampla variedade de plantas e alimentos com significados medicinais e religiosos, aclimatados com sucesso no Brasil pelos cativos africanos e seus descendentes.

A interpretação que serve para o arroz e certas plantas, contudo, não serve para o café, um arbusto igualmente originário do continente africano $^{11} .0$ plano proposto por Carney e Voeks em seu artigo programático pode levar à reificação dos produtos agrícolas que os africanos trouxeram de seu continente, caso o conteúdo especifico das relações sociais que se estruturaram a partir da exploração desses produtos não seja devidamente examinado. A idéia que pretendo desenvolver neste artigo é a de que a presença maciça da população africana escravizada no Vale do Paraíba, em um contexto local e global bastante turbulento, marcado pela competição entre diferentes produtores mundiais pelo controle do artigo e pelo acirramento da resistência escrava, levou à adoção, pelos senhores, de formas de administração da paisagem de suas fazendas que procuravam restringir a autonomia dos cativos no processo de trabalho. Com isso, não quero negar a ação ativa dos escravos na conformação da paisagem das fazendas, mas simplesmente destacar, conforme ressalta Harvey Kaye, os meios pelos quais "a agência das classes subalternas de fato estruturou o poder" das classes dirigentes ${ }^{12}$. Em outro artigo, indiquei como esses mesmos elementos condicionaram as formas arquitetônicas das senzalas nas grandes unidades cafeeiras do Vale do Paraiba, cujos donos buscaram inspiração nos barracões de embarque de escravos da costa da África para impor um modelo militar de moradia escrava ${ }^{13}$. Meu foco agora se volta para a análise do processo correlato que ocorreu nos cafezais.

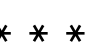

A despeito do que seu nome possa indicar, a espécie arábica do cafeeiro é natural das zonas de bosques montanhosos da Etiópia. Os mercadores árabes, no início do século XVI, estimularam com sucesso a aclimatação da planta no extremo sul da Península Arábica, que passou a ser cultivada intensivamente por camponeses iemenitas. Até fins do século XVII, produção e comercialização do artigo permaneceram sob monopólio islâmico ${ }^{14}$. As familias camponesas procuraram reproduzir as condições originais do cafeeiro: o plantio ocorria à sombra de grandes árvores; no manejo da planta, os arbustos não eram decotados, nem podados, atingindo alturas médias entre 4 e 6 metros; na época da safra, estendiam-se esteiras em baixo dos pés e se sacudiam os cafeeiros, para que apenas os frutos maduros fossem desprendidos; a secagem dos frutos se dava nas próprias esteiras utilizadas na colheita, agora expostas ao sol; por fim, a separação da polpa e do pergaminho do grão era efetuada em mós de pedra ${ }^{15}$.

Como se pode depreender, a produção nesse modelo era necessariamente restrita. Quando holandeses e franceses se apossaram da planta, com vistas ao abastecimento da crescente demanda metropolitana, procuraram adaptá-la ao cultivo em larga escala, com uma organização do trabalho bastante distinta dos padrões camponeses do lêmen. Isto ocorreu ainda no espaço Índico, antes da passagem para o Atlântico ${ }^{16}$. Jean-Louis Alléon-Dulac, ao publicar seu Melánge d'Histoire Naturelle em 1754, regis- 
17

ALLÉON-DULAC, J.-L. Introdução sobre a cultura do café. In: VELLOSO, Frei José Mariano da Conceição. O Fazendeiro do Brazil. Tomo III, "Bebidas Alimentosas", parte I, Café. Lisboa: Oficina de Thadeu Ferreira, 1800. p.128, p.138.

\section{8}

Cf. MARQUESE, Rafael de Bivar. Administração Et Escravidão. Idéias sobre a gestão da agricultura escravista brasileira. São Paulo: Hucitec, 1999. p.121-131.

19

Cf. LABORIE, P.J. Cultura do Café. Plantador de café de São Domingos. In: VELLOSO, Frei José Mariano da Conceição. O Fazendeiro do Brazil. Tomo III, "Bebidas Alimentosas", parte II, Café. Lisboa: Oficina de Thadeu Ferreira, 1800.

\section{0}

Sabe-se, por exemplo, que a difusão da coleção editada por Frei Veloso foi um completo fiasco. Diante do fato de pouquissimos exemplares terem sido vendidos, as autoridades coloniais resolveram distribuir gratuitamente os volumes da coleção. Há várias indicações dando conta do pouco caso dos senhores rurais pelos exemplares que thes foram fornecidos, existindo inclusive registros de que em São Paulo, nas primeiras décadas do século XIX, alguns proprietários utilizavam os volumes d'O Fazendeiro do Brasil para acender fogo. Ver, a respeito, DIAS, Maria Odila Leite da Silva. Aspectos da ilustração no Brasil. In: A interiorização da metrópole e outros estudos. São Paulo: Alameda, 2005. p.111-112.

21

Cf. MARQUESE, Rafael de Bivar. Op.Cit., p.157-167.

22

Cf. TAUNAY, Affonso. História do Café no Brasil. 15 v. Rio de Janeiro: DNC, V.05, 1939. p.14-15. trou que, na ilha de Bourbon (atual Reunião), os cafeeiros eram plantados em alinhamento e decotados quando atingissem a altura de um homem adulto. As razões para tanto eram ditadas pelo emprego do trabalho escravo: o decote facilitava a colheita, "pois os seus ramos mais altos ficam ao porte dos escravos", ao passo que o plantio alinhado, além de deixar "muito agradável e vistosa a perspectiva da fazenda", facultava ao seu senhor "ver com facilidade o trabalho de todos os seus escravos" 17.

Tal manejo - plantio alinhado com decote do arbusto - se fez presente em todos os espaços escravistas do Atlântico que passaram a produzir café em larga escala no século XVIII, isto é, Martinica, Suriname, Jamaica e, sobretudo, Saint Domingue. Após a década de 1790, na esteira do vácuo criado com a revolução dos escravos nesta última colônia e do aumento da demanda nas zonas centrais da economia-mundo, apareceram no mercado mundial novas áreas produtoras do artigo, como Cuba e Brasil. As técnicas elaboradas pelos poderes coloniais holandeses, ingleses e franceses foram veiculadas na América portuguesa, por meio de traduções, desde os primeiros anos do século XIX, destacando-se a notável coleção O Fazendeiro do Brazil, editada em onze volumes entre 1798 e 1806 pelo Frei José Mariano da Conceição Veloso ${ }^{18}$. Em um dos volumes referentes ao café, Veloso inseriu o tratado de P.J.Laborie, cafeicultor escravista de Saint Domingue refugiado na Jamaica, que, apenas dois anos antes, publicara em inglês a primeira edição de seu livro, reportado durante quase todo o século XIX como o manual agronômico mais importante sobre o assunto ${ }^{19}$.

Mesmo que seja difícil documentar a transmissão de técnicas por meio do exame do consumo das publicações contemporâneas 20 , pode-se afirmar que a combinação plantio alinhado / decote dos pés foi adotada no Brasil assim que a atividade cafeeira em larga escala deslanchou. À medida que, na década de 1820, eram montadas as grandes unidades escravistas no Vale do Paraíba, somou-se, à progressiva aprendizagem das técnicas agrícolas, a construção de um saber local. 0 movimento pode ser acompanhado por meio dos impressos agronômicos. Até 1835, os escritos sobre a cafeicultura editados no Brasil cuidaram apenas de propagar as técnicas produtivas antilhanas, no mais das vezes retiradas d'O Fazendeiro do Brazil, sem se referirem concretamente à produção que estava em franco processo de crescimento no médio Vale do Paraiba. Os únicos que escreveram diretamente sobre a produção brasileira entre as décadas de 1820 e 1830 foram alguns viajantes estrangeiros, que estiveram nas províncias do Rio de Janeiro, São Paulo e Minas Gerais21.

Em 1836, contudo, veio a lume o primeiro trabalho redigido com base na experiência acumulada na produção de café no Brasil. Seu autor, o padre João Joaquim de Ferreira de Aguiar, na ocasião com 31 anos de idade, residira por cinco anos na fazenda Desengano Feliz, município de Valença - que Affonso Taunay supõe ter pertencido a Manuel Jacinto Nogueira da Gama, marquês de Baependy22 - observando cuidadosamente as técnicas elaboradas localmente. Seu objetivo, ao trazê-las a público, era justamente o de indicar a cisão que representavam em relação às técnicas caribenhas. A prática local demonstrara que os solos adequados para a cultura cafeeira eram os existentes nos morros de meia-laranja, típicos da paisagem do Vale e recobertos de mata virgem; os cafezais das terras baixas, apesar de vistosos, rendiam poucos frutos. 0 preparo do terreno se dava por meio da derrubada e queima da mata, que não envolvia dispêndio excessivo de tempo de trabalho e possibilitava o crescimento vigoroso dos pés de café. 
23

Cf. AGUIAR, João Joaquim Ferreira de. Pequena memória sobre a plantação, cultura e colheita do café. Rio de Janeiro: Imprensa Americana de I.P.da Costa, 1836. p.6-11.

\section{4}

LABORIE, P.J. Cultura do Café. Plantador de café de São Domingos. In: VELLOSO, Frei José Mariano da Conceição. O Fazendeiro do Brazil. Tomo III, "Bebidas Alimentosas", parte II, Café. Lisboa: Oficina de Thadeu Ferreira, 1800. p.159.

\section{5}

Cf. LAËRNE, C.F.van Delden. Brazil and Java. Report on Coffee-Culture in America, Asia, and Africa. Londres-Haia: Martinus Nijhoff, 1885. p.276. Seus dados são reproduzidos também em MUNIZ, Célia Maria Loureiro. Os donos da terra. Um estudo sobre a estrutura fundiária do Vale do Paraiba Fluminense, século XIX. Dissertação de Mestrado. Universidade Federal Fluminense, Niterói (ICHF/UFF), 1979. p.25.

\section{6}

Cf. AGUIAR, João Joaquim Ferreira de. Op.Cit., p.12.

27

Cf. MORGAN, P. Task and Gang Systems. The organization of labor on New World plantations. In: INNES, P. (org.). Work and labor in early America. Chapel Hill: The University of North Carolina Press, 1988.

28

Cf. LABORIE, P.J. Op.Cit., p.216-217.
0 plantio obedecia a uma linha vertical do cume do morro até sua base, distando os pés entre si de catorze a dezesseis palmos ( 3 a 3,5m), conforme a qualidade do terreno; nos três primeiros anos de formação do cafezal, aproveitava-se o amplo espaço entre as fileiras para o cultivo de milho, feijão e mandioca, com o duplo objetivo de garantir sombreamento para os pés recém-plantados e manter a escravaria trabalhando de forma produtiva no amanho de mantimentos. No manejo do arbusto, decotava-se o cafeeiro quando atingisse a altura de dez palmos $(2,2 \mathrm{~m})$, para facilitar a apanha dos frutos e evitar a quebra dos ramos na operação da colheita; as capinas, por sua vez, eram efetuadas três vezes ao ano. Como o rendimento decrescente dos cafeeiros velhos, com mais de duas décadas, não compensava o custo de seu manejo, todo ano era necessário recorrer ao plantio de novos cafezais, à taxa de $10 \%$ do total de pés existentes na fazenda 23 .

Uma rápida comparação com o manual de Laborie servirá para compreender no que essas técnicas se afastavam do padrão caribenho. Em Saint Domingue pré-revolução, era prática comum os fazendeiros plantarem os arbustos em quincunces, "cuja vantagem é unir as fileiras, e por conseqüência ganhar terreno" 24 . 0 afastamento padrão veiculado por Laborie, de seis pés quadrados por quincunce, significava cerca de 15.700 pés por alqueire geométrico (48.400 $\mathrm{m}^{2}$ ). Se lermos a tabulação elaborada por Laërne25, será possivel observar que, no afastamento mínimo anotado por Aguiar, havia cerca de 5.100 arbustos por alqueire geométrico.

Qual era a lógica subjacente a esse aparente desperdício de terreno no Vale do Paraiba? Antes de tudo, ele guardava relação direta com a quantidade de terras virgens disponíveis no Brasil, sem termos de comparação com a oferta reduzida desse insumo nas ilhas caribenhas. 0 ponto central, entretanto, remetia-se à organização do processo de trabalho. 0 alinhamento vertical dos pés, com grande espaçamento entre as fileiras, obedecia ao primado da visualização como meio de controle dos trabalhadores, algo que já vinha sendo adotado desde o Índico, mas que adquiriu sentido novo nas fazendas do Vale. Na safra ou nas capinas, cada escravo era alocado em uma fileira de arbustos, principiando a faina pelo alto dos morros até chegar à sua base: o feitor ou capataz, na parte inferior, teria pleno controle visual sobre as atividades, observando - caso das capinas - se a linha de cativos prosseguia no mesmo passo ditado pelos trabalhadores das pontas, ou - caso da safra - se não deixaram de colher nenhuma árvore ou se as danificaram ${ }^{26}$.

As fazendas de café brasileiras combinavam assim as duas modalidades básicas de organização do processo de trabalho escravo presentes nas demais regiões de plantation do Novo Mundo, as turmas sob comando unificado (gang system) e o sistema de tarefas individualizado (task system) 27 . No entanto, o sistema de tarefas por aqui adotado se afastava sensivelmente do que se empregava nas unidades cafeeiras caribenhas. Laborie, dando conta da prática corrente em Saint Domingue, registrou que se exigia dos escravos, nos anos de boa safra, uma tarefa fixa de colheita, cabendo ao cativo o usufruto de tempo livre após seu cumprimento28. Aguiar, por sua vez, compôs seu manual no exato momento em que os fazendeiros do Brasil estavam inovando na matéria. Em suas palavras,

cada trabalhador pode muito bem colher por dia três a três e meio, e mesmo quatro alqueires nos anos abundantes; as mulheres de ordinário são mais destras neste serviço: alguns fazendeiros costumam contentar-se com três alqueires, 
29

AGUIAR, João Joaquim Ferreira de. Pequena memória sobre a plantação, cultura e colheita do café. Rio de Janeiro: Imprensa Americana de I.P.da Costa, 1836. p.12-13.

30

Cf. WERNECK, Francisco Peixoto de Lacerda (barão de Pati do Alferes). Memória sobre a Fundação de uma Fazenda na Província do Rio de Janeiro (1a ed: 1847). Org. Eduardo Silva. Rio de Janeiro: Fundação Casa de Rui Barbosal Brasília: Senado Federal, 1985. p.67.

31

Como esclarece um agrônomo recente, "o ciclo bienal de produção está intimamente ligado ao sistema de cultivo de café adotado no Brasil, a pleno sol, em que os cafeeiros necessitam vegetar em um ano para produzir bem no ano seguinte". MATIELLO, José Braz. O Café. Do cultivo ao consumo. São Paulo: Globo, 1991. p.18-19. deixando retirar-se do trabalho o que os apresenta a qualquer hora; outros porém pagam o excesso daquela tarefa, se o trabalhador se presta a continuar até se colherem todos: convém muito que os feitores tenham o maior desvelo em não consentir que se colham os frutos ainda não bem maduros, porque estes não podem dar bom café; nem que se desfolhem os ramos, ou se quebrem em prejuizo da futura colheita. Alguns fazendeiros porém, para não darem segunda corrida aos cafezais, colhem logo todos os frutos, ainda os mal maduros, e afirmam que, seguindo o processo de seca com os bem maduros, nenhuma diferença se nota por fim entre uns e outros; o que, sendo assim, é digno de aproveitar-se ${ }^{29}$.

Pode-se ler, na passagem, três procedimentos distintos em relação à organização do trabalho na colheita. Nos dois primeiros casos, a tarefa a ser cumprida obrigatoriamente pelo escravo era fixada em três alqueires, com rigorosa supervisão do feitor para impedir a apanha de frutos verdes. A diferença entre ambos remetia-se à forma de estimular o trabalhador, ou com a cessão de tempo livre caso o escravo cumprisse a tarefa (sistema corrente nas Antilhas), ou com recompensa monetária caso excedesse 0 quantum mínimo exigido. No terceiro método, o que importava ao fazendeiro era antes a quantidade do que a qualidade dos frutos, com a máxima economia de trabalho: colhendo frutos verdes e maduros, era evidente que o quantum retirado por cada escravo, em anos de safras boas, seria consideravelmente maior do que os três alqueires exigidos como padrão.

Documentos posteriores dão conta de que o terceiro procedimento se tornou a regra no Vale. Veja-se, por exemplo, o caso do mais famoso manual agronômico elaborado na região, escrito pelo poderoso cafeicultor vassourense Francisco Peixoto de Lacerda Werneck, barão de Pati do Alferes, publicado inicialmente em 1847 nas páginas do Auxiliador da Indústria Nacional, reunido em livro neste mesmo ano e reimpresso com acréscimos duas vezes após a morte do autor, em 1863 e 1878. A passagem referente à colheita já foi citada por outros historiadores, mas cabe transcrevê-la novamente:

A colheita varia conforme sua abundância; se ela for desigual, um apanhador não pode às vezes dar mais do que um a três alqueires; porém se ele se torna todo maduro, então deve a tarefa passar a cinco, seis e sete alqueires. Ás horas de medir, que deve ser ao entrar do sol, o administrador deve estar presente a fim de fazer castigar aqueles que não deram a tarefa, que se deve graduar conforme o estado do café e as forças do individuo. Um dos melhores expedientes que (em princípio quando os meus escravos não sabiam apanhar o café) estabeleci, e de que tirei muito bom resultado, foi o dos prêmios, v.g. marcava cinco alqueires como tarefa, e dizia-Ihes: todo aquele que exceder, terá por cada quarta 40 réis de gratificação; com este engodo que era facilmente observado, consegui que apanhassem sete alqueires, que ficou depois estabelecido como regra geral 30 .

As variações bienais das safras eram bastante comuns, como sempre ocorre quando os cafeeiros são plantados sem sombreamento ${ }^{31}$. De todo modo, ressalta-se o fato de a tarefa mínima em um ano bom ser sensivelmente mais elevada do que a registrada dez anos antes por Aguiar. Também se destaca a mensuração individual das tarefas, a serem estabelecidas pelo administrador conforme sua avaliação a respeito do volume da safra; ainda que a colheita fosse realizada em turmas, a punição ou recompensa seria aplicada individualmente a cada trabalhador. Por fim, em uma passagem na qual a arrogância senhorial se manifesta sem meias palavras, observase que o incentivo para a ampliação da colheita, após o recolhimento do quantum mínimo, seria monetário. 
32

A citação de Laërne se encontra na p.301 de seu livro; a de Honório Carneiro Leão, em seu "Discurso autobiográfico, pronunciado no Senado na sessão de 31 de julho de 1854". In: Revista do Instituto Histórico e Geográfico Brasilieiro, V.236, p.275-284, julho-setembro de 1957, p.281 (agradeço Ricardo Salles pela sugestão deste documento). Stanley Stein (Vassouras. Um municipio brasileiro do café, 1850-1900. (1ª ed: 1957; trad. port.) Rio de Janeiro: Nova Fronteira, 1990, p. 207, n.22) e Carlos Eugênio Marcondes de Moura (O Visconde de Guaratinguetá. Um fazendeiro de café no Vale do Paraiba (1a ed: 1976). São Paulo: Studio Nobel, 2002, p. 162, n.5) transcrevem trechos de inventários de fazendeiros de Vassouras e Guaratinguetá com anotações referentes ao pagamento de escravos por trabalho de colheita aos domingos. Por fim, nas "Instruções geraes para a administração das fazendas" dos herdeiros do barão de Nova Friburgo, elaboradas em 1870 e analisadas abaixo, lê-se que "os domingos e horas de recreio não devem ser preenchidos por serviços, senão na maior necessidade, ou por livre vontade do escravo com recompensa de pagamento". "Instruções geraes para a administração das fazendas" (23 de fevereiro de 1870). In: ARAÚJO, E. (org.) Negro de corpo e alma. Mostra do Redescobrimento. Brasil 500 anos. São Paulo: Fundação Bienal de São Paulo, 2000. p.109.

33

LABORIE, P.J. Cultura do Café. Plantador de café de São Domingos. In: VELLOSO, Frei José Mariano da Conceição. O Fazendeiro do Brazil. Tomo III, "Bebidas Alimentosas", parte II, Café. Lisboa: Oficina de Thadeu Ferreira, 1800. p.49. Quanto ao processo produtivo do café, ver as sugestivas considerações de GORENDER, Jacob. O escravismo colonial. (1 ${ }^{\text {a }}$ ed: 1978) São Paulo: Ática, 1985. p.214.

34

Esses dados foram retirados, respectivamente, das seguintes fontes: GEGGUS, David P. Sugar and Coffee Cultivation in Saint Domingue and the Shaping of the Slave Labor Force. In: BERLIN, I.; MORGAN, P. (org.). Cultivation and Culture. Labor and the Shaping of Slave Life in the Americas. Charlottesville, Va.: University Press of Virginia, 1993. p.77; HIGMAN, B.W. Jamaica Surveyed. Plantation Maps and Plans of the Eighteenth and Nineteenth Centuries. Kingston: University of the West Indies Press, 2001.p.159-91; NOA, Tranquilino Sandalio de. "Memoria publicada por la Real Sociedad Patriotica sobre esta cuestión del programa: 'Cuáles son las causas a que puede atribuirse la decadencia del precio del café, y si en las actuales circunstancias de su abatimiento seria perjudicial empreender su cultivo, o prudente abandonarlo'. Programa publicado en el Diário del Gobierno de la Habana en 10 de abril de 1829". In: Actas de las Juntas Generales que celebro la Real Sociedad Económica de Amigos del País de la Habana, en los dias 14, 15 y 16 de diciembre de 1829. Havana: Imprenta del Gobierno, 1830, pp.131-133; TAUNAY, Carlos Augusto. Manual do Agricultor Brasileiro (1a ed: 1839). Org. Rafael de Bivar Marquese. São Paulo: Companhia das Letras, 2001. p.130.
Há vários registros da segunda metade do século XIX que comprovam a disseminação da prática do pagamento em numerário como estímulo para que os escravos colhessem acima dos mínimos estabelecidos pelos administradores. Em julho de 1854, ao discursar no Senado imperial sobre as origens de sua fortuna, Honório Hermeto Carneiro Leão (futuro marquês do Paraná) esclareceu seus pares que o segredo dela estava na exploração "racional" dos escravos, isto é, na imposição de grande carga de trabalho: "se fiz tão avultada colheita [20.000 arrobas em 1852], não é porque tenha empregado grande número de braços; há fazendeiros que têm o duplo e ainda mais, e entretanto colhem menos. Não tenho na fazenda [do Lordelo, no atual município de Sapucaia, Rio de Janeiro] mais de 150 escravos entre grandes e pequenos; emprego poucas pessoas livres; pago aos meus escravos o que colhem nos dias de guarda, e o excesso de sua respectiva tarefa nos dias de serviço". Trinta anos depois, Laërne escreveu que na "zona do Rio", isto é, no Vale do Paraíba, mas não no oeste paulista, o estipêndio monetário era adotado para "encorajar o escravo que colheu mais. Como regra, então, ele ganha 200 réis por alqueire durante as primeiras quatro ou cinco semanas da safra, soma que aumenta para 240 réis por alqueire no restante da colheita". Quando a safra era abundante, a colheita avançava aos domingos, e, para tanto, o trabalho da escravaria deveria ser remunerado 32 .

Por que os senhores brasileiros se viram ante a necessidade de incentivar seus escravos acenando com ganhos monetários em caso de sobre-trabalho? Afora os anseios dos cativos para ampliarem suas margens de autonomia em relação a seus senhores, por meio do usufruto de uma economia própria que englobava não apenas suas roças mas também todos recursos extras que porventura conseguissem amealhar, devemos lembrar as imposições do processo de produção do café. A safra (colheita e beneficiamento) constituia o gargalo da atividade, o ponto que determinava as dimensões ideais da força de trabalho na fazenda. Laborie fora claro quanto a isso, ao escrever que " $a$ pessoa que se estabelece deve calcular com cuidado e só estender suas plantações à proporção dos braços de que pode dispor" 33 .

Os fazendeiros do Vale, contudo, levaram essa equação ao limite. Por um lado, o esquema de administração da paisagem que adotaram (plantio alinhado vertical com grande espaçamento entre os pés) facilitava a supervisão estrita das turmas de escravos que labutavam em unissono, tanto nas capinas como na colheita; por outro lado, a adoção, na safra, de um método de gestão que combinava trabalho coletivo, apanha sem escolha dos frutos e mensuração individual permitia a imposição de uma taxa elevada de trabalho aos cativos. Na cafeicultura de Saint-Domingue, a um escravo de eito eram atribuidos usualmente entre 1.000 e 1.500 pés de café, o mesmo que se imputava aos escravos jamaicanos. Em Cuba, estimava-se que um cativo de roça cultivaria em média 2.000 pés, número semelhante ao do início da cafeicultura no Brasil ${ }^{34}$. Nas décadas de 1830 e 1840, com a progressiva especialização das fazendas do Vale do Paraiba, a quantidade alocada aos trabalhadores escravizados aumentou de forma substantiva. 0 diplomata suiço Johann Jakon von Tschudi, ao percorrer a zona de Cantagalo em 1860, pôde consultar as anotações de um fazendeiro referentes às safras em meados do século. Interessa-nos aqui os dados relativos ao periodo de 1847 a 1850, quando Werneck pôs no mercado seu manual agronômico: os aproximadamente 72.000 pés da fazenda (com uma produtividade média de 63,9 arrobas por arbusto) eram cultivados por 34 trabaIhadores de roça, perfazendo assim uma média de 3.934 pés por cativo, 
Cf. TSCHUDI, J.J. Viagem às Províncias do Rio de Janeiro e São Paulo (1 ${ }^{\text {a }}$ ed: 1866; trad.port.) São Paulo: Edusp - Belo Horizonte: Itatiaia, 1980. p.41.
36

Cf. SCHNOOR, Eduardo. Das casas de morada às casas de vivenda. In: CASTRO, H.M. Mattos de; SCHNOOR, E. (org.). Resgate. Uma janela para o Oitocentos. Rio de Janeiro: Topbooks, 1995. p.41. 37

Cf. COSGROVE, Denis. Social Formation and Symbolic Landscape. New Ed. Madison: The University of Wisconsin Press, 1996. uma quantidade assombrosa em vista dos padrões antilhanos anteriores ${ }^{35}$. Não surpreende, portanto, que, em anos de safra abundante, senhores e administradores lançassem mão de um leque de incentivos para dar conta da colheita e do beneficiamento, dentre os quais se destacava o pagamento por apanha extra e por trabalho aos domingos.

Essa taxa de exploração do trabalho escravo foi certamente um dos elementos que impulsionaram o deslanche da cafeicultura brasileira e 0 domínio absoluto que passou a exercer no mercado mundial do produto a partir da década de 1830. Em resposta a um quadro econômico internacional bastante competitivo, que exigia aumento constante de produtividade para nele se manter, mas também diante de uma escravaria majoritariamente africana, masculina, jovem, refratária ao mando senhorial, os proprietários do Vale do Paraíba adotaram estratégias de organização do processo de trabalho que pretendiam aumentar seu grau de controle sobre os escravos, fazendo-os trabalhar cada vez mais, porém com pequenas aberturas para que pudessem se valer de uma economia própria. Tal era a lógica subjacente a um padrão de administração da paisagem que envolvia tão grande desperdício de recursos naturais.

A apreensão simbólica pelos senhores desse padrão pode ser observada em uma famosa pintura parietal da fazenda Resgate, em Bananal, província de São Paulo, composta na segunda metade da década de 1850 por José Maria Villaronga, logo após a casa de vivenda ter sido reformada e ampliada 36 . Recorrendo a um artifício que esteve na origem renascentista da pintura de paisagem 37 , o pintor abriu a "janela" da sala de jantar da fazenda para as linhas verticais dos cafezais perfeitamente simétricos e afastados, cujo produto fluia como que naturalmente, sem a necessidade de trabalho humano, para os cofres de seu proprietário.

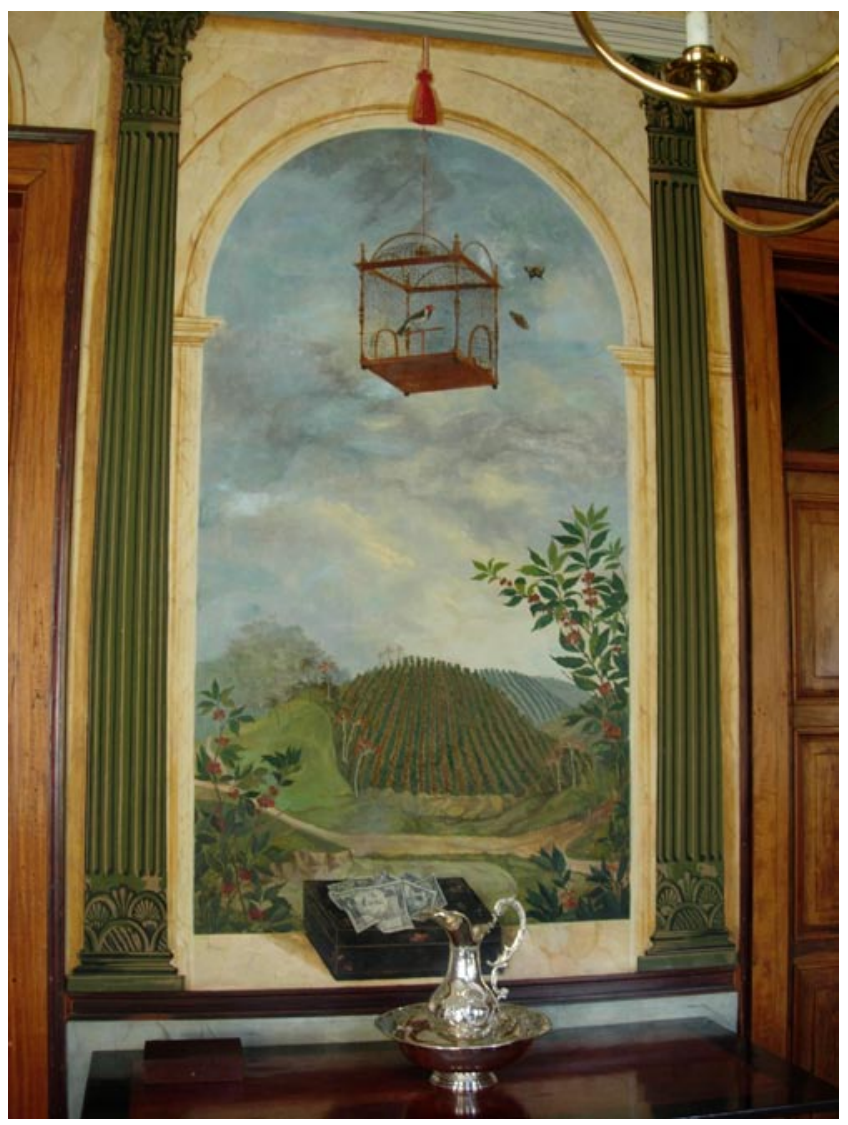

Pintura parietal em trompe-l'oeil da sala de jantar da fazenda Resgate, Bananal, São Paulo, c.1860; fotografia de Reinaldo Funes Monzote, novembro de 2005. 
38

STEIN, Stanley. Vassouras. Um municipio brasileiro do café, 1850-1900. (1a ed: 1957; trad. port.) Rio de Janeiro: Nova Fronteira, 1990. p.200. Ver também SLENES, Robert W. 'Malungo, ngoma vem!' África coberta e descoberta no Brasil. In: ARAÚJO, E. (org.) Negro de corpo e alma. Mostra do Redescobrimento. Brasil 500 anos. São Paulo: Fundação Bienal de São Paulo, 2000. p.218.

39

"Instruções geraes para a administração das fazendas" (23 de fevereiro de 1870). In: ARAÚJO, E. (org.) Negro de corpo e alma. Mostra do Redescobrimento. Brasil 500 anos. São Paulo: Fundação Bienal de São Paulo, 2000. p.110.

40

Cf. LAËRNE, C.F.van Delden. Brazil and Java. Report on Coffee-Culture in America, Asia, and Africa. Londres-Haia: Martinus Nijhoff, 1885. p.293; ver também as "Instruções geraes para a administração das fazendas" (23 de fevereiro de 1870). In: ARAÚJO, E. (org.) Negro de corpo e alma. Mostra do Redescobrimento. Brasil 500 anos. São Paulo: Fundação Bienal de São Paulo, 2000. p.108.

41

Cf. MACHADO, Maria Helena P.T. Crime e escravidão. Trabalho, luta e resistência nas lavouras paulistas, 1830-1888. São Paulo: Brasiliense, 1987. p.68; GARCIAA, Gloria. Vertebrando la resistencia: la lucha de los negros contra el sistema esclavista, 1790-1845. In: GONZÁLEZ-RIPOLL, M.D.; NARANJO, C.; FERRER, A.; GARCÍA, G.; OPATRNÝ. J.. El rumor de Haiti en Cuba: Temor, raza y rebeldia. Madri: Consejo Superior de Investigaciones Científicas, 2004. p.241.
Os escravos podem ter desaparecido da pintura de Villaronga, mas eles estavam lá, trabalhando nos cafezais de Manoel de Aguiar Vallim e de todos os demais fazendeiros do Vale do Paraiba. Trabalhando, enriquecendo seus donos e resistindo. Stanley Stein, com base em entrevistas realizadas na década de 1940 com ex-escravos para seu livro sobre Vassouras, descreveu em páginas admiráveis o cotidiano de trabalho no eito, sempre embalado pela cantoria dos jongos. As turmas de cativos labutavam nas fileiras de café sob a supervisão constante e ameaçadora dos capazes, "mas se a vigilância afrouxava, os trabalhadores aproveitavam a oportunidade para moderar a atividade enquanto homens e mulheres acendiam cachimbos ou se recostavam momentaneamente nas enxadas para enxugar o suor" 38.

A "cera" dos escravos era algo bem conhecido dos senhores, assim como seus esforços para se apossarem do comando do processo de trabalho, não raro tendo capatazes e feitores por parceiros, que, deste modo, procuravam atenuar as tensões inerentes à função. Os filhos de Antonio Clemente Pinto (barão de Nova Friburgo), ao assumirem a herança fabulosa do pai falecido em 1869, composta por quinze fazendas e cerca de dois mil escravos nos municípios de Cantagalo, São Fidélis e Nova Friburgo, elaboraram um documento bastante minucioso para uniformizar a administração das diversas unidades cafeeiras da família. Semelhante, no conteúdo das prescrições, aos manuais agrícolas coevos, a peça firmada em fevereiro de 1870 era todavia mais detalhada no que se referia aos embates com os escravos. A respeito da colheita, por exemplo, determinava que a tarefa seria estabelecida pelo administrador de cada uma das fazendas ao fim da jornada diária, declarando-a todas as noites aos escravos no alinhamento de vistoria realizado no terreiro, antes de serem trancados nas senzalas; no dia seguinte, o próprio administrador inspecionaria os cestos colhidos individualmente, para verificar se a tarefa fora cumprida. 0 alvo da medida prescrita era, antes de tudo, a qualidade do comando no eito: nos termos do documento, "se deve banir a idéia que o feitor pouco tenha a fazer na colheita, por esta se fazer por tarefa, do contrário nunca precisará mais o dono da fazenda da autoridade do feitor" 39.

A acomodação entre os feitores e os cativos derivava, em parte, da prática de distribuição dos escravos de roça em turmas (ternos, na linguagem oitocentista). Nas grandes unidades cafeeiras do Vale, com escravarias de eito com mais de 50 trabalhadores, a cadeia de comando era composta usualmente pelo administrador geral da fazenda, pelos feitores de terreiro e de partido e pelos capatazes (também chamados feitores de roça), os últimos quase sempre recrutados na própria escravaria. Laërne, que observou cuidadosamente as propriedades dos irmãos Antonio Clemente Pinto (filho) e Bernardo Clemente Pinto Sobrinho na região de Cantagalo, afirmou que cada capataz ou feitor se responsabilizava pelo controle de ternos compostos por 20 a 25 escravos, homens e mulheres; cada um desses grupos tinha um(a) cozinheiro(a) cativo(a), que preparava as refeições no eito; quando trabalhavam juntos, os diversos ternos eram diretamente supervisionados pelo administrador 40 .

Forçados pelos senhores a extraírem muito trabalho dos escravos, feitores e capatazes tinham contudo que negociar diariamente com eles nas lidas do campo ${ }^{41}$. Um caso analisado pelos historiadores Bryan McCann e Camilla Agostini é particularmente relevante para os propósitos deste artigo. Em 17 de outubro de 1866, foi assassinado, na fazenda do comendador Venâncio José Gomes da Costa, na freguesia de Sacra Família do 
0 processo crime referente a este caso encontra-se depositado no Centro de Documentação Histórica da Universidade Severino Sombra, em Vassouras ( $2^{\circ}$ Ofício, caixa 467). Agradeço a enorme gentileza de Camilla Agostini, que me franqueou a consulta de suas anotações de pesquisa; em seu fichário, base de sua dissertação de mestrado (AGOSTINI, Camila. Africanos no cativeiro e a construção de identidades no além-mar. Vale do Paraiba, sécuIo XIX. Dissertação de Mestrado. DH/IFCH/ Unicamp, 2002. p.44-56), o processo em questão está catalogado como PC - 066. Ver também McCANN, Bryan Daniel. The Whip and the Watch: Overseers in the Paraiba Valley, Brazil. In: Slavery and Abolition. V.18, n. 2, p.30-47, August 1997, p.38-42.
Tinguá, Vassouras, o feitor português Manoel Duarte Simões ${ }^{42}$. Tratava-se, sem dúvida, de uma fazenda muito problemática. Seu proprietário era, na ocasião, presidente da Câmara Municipal de Baependi, no sul de Minas, encontrando-se ausente de Vassouras durante todo o episódio. Simões fora contratado apenas duas semanas antes de seu assassinato, em plena fase final da safra de café, para substituir o feitor Francisco Bernardes da Costa, que, não obstante, continuara a residir em terras da fazenda. Ao longo do processo, alguns dos escravos afirmaram que Francisco Bernardes fora despedido por fazer vistas grossas ao fato de que cativos roubavam café para repassá-lo, em troca de cachaça e tabaco, a Jerônimo Siqueira de Vasconcelos, um outro ex-feitor da propriedade - antes de sua aquisição pelo comendador Venâncio - que nela permanecera como morador e na qual mantinha uma pequena venda. Francisco Bernardes, entretanto, apresentou explicação distinta. Em suas palavras, ele havia se demitido "por não poder suportar os escravos e tolerar seus desregramentos". "Quando feitor da fazenda do comendador Venâncio", prosseguiu, "muitas vezes percorrendo as roças, dava com café oculto e com garrafas de aguardente, que mesmo na fazenda, nas próprias senzalas, os pretos se embriagavam e que a astúcia deles era tal que tiravam à noite tábuas do soalho da senzala e por aí saíam à noite e iam comprar aguardente e vender o café que furtavam". Seu juizo sobre a matéria era peremptório: "todos os escravos em geral são mal comportados e desobedientes e refratários ao cumprimento de suas obrigações".

Seja como for, demitido ou demissionário, o contraste entre o comando de Francisco Bernardes e o de Manoel Duarte Simões aparece em quase todos os depoimentos dos escravos. Segundo Bárbara Maria da Conceição, que realizava trabalhos domésticos na casa de Jerônimo Siqueira, "os escravos não gostavam de Simões, porque Ihes não perdoava, e estava sempre em cima deles, gostando mais os mesmos escravos de Francisco Bernardes, com quem estavam acostumados, não os castigava, deixava-os na roça e ia dormir e os negros faziam o mesmo". 0 mais significativo para esta análise, contudo, está em outro ponto. Simões, ao assumir o cargo de feitor, não só interditou - valendo-se do chicote - os contatos dos escravos com Jerônimo Siqueira, como igualmente tentou impor novo ritmo de trabalho para a urgência da colheita em sua fase final. A tarefa acordada entre o ex-feitor Francisco e a escravaria da roça era de três alqueires. Simões passara a exigir que os escravos "dessem tarefa de quatro alqueires e que aqueles que a não dessem seriam castigados" (depoimento do escravo Adão). No dia anterior a seu assassinato, Simões mandara fincar um mourão no terreiro de roça defronte aos cafezais que estavam na apanha, sinalizando com clareza o que faria com os cativos que não cumprissem as novas determinações de trabalho.

Esse episódio demonstra - na figura de Francisco Bernardes - a camaradagem ou a acomodação que poderiam surgir nos contatos cotidianos entre feitores de roça e escravos, porém igualmente indica - na figura de Simões - as tensões envolvidas nos esforços para aumentar a produção de café. 0 reconhecimento senhorial da complexidade dessas hierarquias fica claro pelo que ocorreu, em 1881, na fazenda Resgate, a mesma decorada por Villaronga duas décadas antes. No início de uma manhã de segundafeira, mês de setembro, o terno sob o comando do feitor escravo Antonio Inácio, após a forma no terreiro, partira para trabalhar em uma fazenda vizinha à Resgate, a Três Barras, também pertencente à viúva de Manoel 
43

As informações sobre este processo, que se encontra depositado no Museu Histórico e Pedagógico Major Dias Novais, Cruzeiro-SP (Cartório Criminal de Bananal, caixa 44, n.979), foram retiradas do trabalho de OLIVEIRA Jr., Alfredo Roberto de. Café e escravidão no Caminho Novo da Piedade: sociabilidades e conflitos no mundo da escravidão (Bananal, 1850-1888). Relatório Final de Iniciação Científica Fapesp. São Paulo: DH/FFLCH/USP, 2006. p.82-98.

\section{4}

Cf. FLORENTINO, Manolo; GÓES, José Roberto. Parentesco e familia entre os escravos de Vallim. In: CASTRO, H. M. Mattos de; SCHNOOR, E. (org.). Resgate. Uma janela para o oitocentos. Rio de Janeiro: Topbooks, 1995.

\section{5}

Cf. FRAGOSO, João; RIOS, Ana Lugão. Um empresário brasileiro dos oitocentos. In: CASTRO, H. M. Mattos de; SCHNOOR, E. (org.). Resgate. Uma janela para o oitocentos. Rio de Janeiro: Topbooks, 1995. p.200. do Aguiar Vallim, falecido em 1878. Um dos membros da turma, o escravo marceneiro Marcolino, sentiu frio e obteve autorização de seu feitor para regressar à senzala e pegar uma manta. Ao chegar ao quadrado da sede, foi interceptado por Lourenço, escravo feitor de terreiro, que, após ríspido bateboca sobre a obrigação de acompanhar seu terno, deu-lhe uma relhada. Marcolino, em resposta, esfaqueou Lourenço e também Clemente, um escravo feitor de outra turma de roça que correra em auxilio de Lourenço. Nenhum dos dois feridos faleceu, mas, mesmo assim, abriu-se processo 43 .

Os depoimentos das testemunhas e dos informantes são muito significativos a respeito da organização do trabalho e das relações entre comandantes e comandados. A Resgate era, na ocasião, uma fazenda velha, com meio século de exploração ininterrupta. Sua escravaria também estava envelhecida e, mais importante, sedimentada em uma comunidade relativamente coesa ${ }^{44}$. 0 já idoso Marcolino, por exemplo, com 61 anos em 1881, ainda que fosse solteiro e tivesse sofrido o trauma de ser vendido no tráfico interno, de São Luis do Maranhão natal para o fundo do Vale do Paraíba paulista, residia na fazenda há 21 anos. Comunidade coesa, entretanto, não equivale à ausência de conflito. De acordo com vários testemunhos, inclusive de personagens centrais na hierarquia da Resgate, como sua dona (a viúva Domiciana Maria de Almeida Vallim), seu filho (Manoel de Aguiar Vallim) e seu administrador (Daniel de Siqueira Bueno), a reação de Marcolino ao esfaquear as duas vitimas decorreu em parte de uma falha grave delas. Afinal, nas palavras do administrador, Marcolino estava "unicamente sujeito ao feitor de roça de nome Antonio Ignácio". Clemente, mesmo que feitor de roça, "nenhum poder ou autoridade" tinha sobre o acusado, haja vista "que era feitor, mas de um outro terno de escravos, a que o acusado não pertencia". A composição e a cadeia de mando interna às turmas, eis o que afirmou, deveriam ser respeitadas para que tudo permanecesse em ordem. Diante disso, é possivel afirmar que acordos informais sobre as condições de trabalho no eito estabelecidos entre um capataz e seu respectivo terno poderiam, eventualmente, permanecer desconhecidos aos senhores e prepostos imediatos.

Resumindo: a proporção espantosa de pés de café por escravo de roça adotada pelos fazendeiros do Vale do Paraiba - na Resgate essa taxa girava, em 1878, em torno de 5.000 arbustos por trabalhador ${ }^{45}$ - não impediu que seus cativos se opusessem, com as armas disponiveis, à demanda de trabalho que lhes era imposta. A própria paisagem descontínua das unidades produtivas forneceu oportunidades para a resistência. A topografia dos mares de morros, bem como o fato de os pés de café não serem alocados em todos os outeiros, davam feição bem variada às terras das propriedades cafeeiras. De acordo com a altitude em que se situava a fazenda, as fileiras eram dispostas ou nas faces dos morros que recebiam o sol da manhã ("noruegas") ou nas que eram ensolaradas à tarde ("soalheiras"). Como se leu páginas atrás, durante o periodo de crescimento dos arbustos, cultivava-se milho e feijão entre as fileiras bastante espaçadas dos pés de café; baixios, várzeas e brejos, inadequados ao cafeeiro, eram cultivados com arroz e cana. Os arbustos assim plantados permaneciam produtivos por no máximo 25 anos, mas seus rendimentos eram perceptivelmente decrescentes a partir de 15 anos. Para se manter a produção em patamares estáveis, fazia-se necessário plantar constantemente pés de café em matas de derrubada, com vistas à substituição dos arbustos velhos e improdutivos prestes a serem convertidos em pasto ou roças de 
Ver, a respeito, afora a detalhada descrição de LAËRNE, C.F.van Delden. Brazil and Java. Report on Coffee-Culture in America, Asia, and Africa. Londres-Haia: Martinus Nijhoff, 1885. p.253382, o trabalho de FRAGOSO, João Luis Ribeiro. Sistemas agrários em Paraiba do Sul (18501920). Dissertação de Mestrado. Rio de Janeiro: IFCH/UFRJ, 1983.

\section{7}

"Instruções geraes para a administração das fazendas" (23 de fevereiro de 1870). In: ARAÚJO, E. (org.) Negro de corpo e alma. Mostra do Redescobrimento. Brasil 500 anos. São Paulo: Fundação Bienal de São Paulo, 2000. p.110.

\section{8}

Ver, respectivamente, STEIN, Stanley. Vassouras. Um município brasileiro do café, 1850-1900. (1a ed: 1957; trad.port.) Rio de Janeiro: Nova Fronteira, 1990. p.177; GOMES, Flávio dos Santos. Histórias de quilombolas. Mocambos e comunidades de senzalas no Rio de Janeiro, século XIX. (Edição revista e ampliada) São Paulo: Companhia das Letras, 2006. p.6569; OLIVEIRA Jr., Alfredo Roberto de. Café e escravidão no Caminho Novo da Piedade: sociabilidades e conflitos no mundo da escravidão (Bananal, 1850-1888). Relatório Final de Iniciação Científica Fapesp. São Paulo: DH/FFLCH/USP, 2006. p.43; AGOSTINI, Camila. Africanos no cativeiro e a construção de identidades no além-mar. Vale do Paraiba, século XIX. Dissertação de Mestrado. DH/IFCH/Unicamp, 2002. p.23.

\section{9}

Cf. LAËRNE, C.Fvan Delden. Brazil and Java Report on Coffee-Culture in America, Asia, and Africa. Londres-Haia: Martinus Nijhoff, 1885. p.294-295. subsistência dos escravos ${ }^{46}$. A estratégia de destruição "administrada" dos recursos florestais, recomendada pelos agrônomos do Vale desde os anos trinta, foi reiterada, décadas depois, em duas instruções para a gestão das fazendas dos herdeiros do barão de Nova Friburgo. Na primeira delas, liase que "nenhuma derrubada pode ser feita sem ordem do administrador geral"; na segunda, estipulava-se que "os terrenos dos cafezais velhos, quando forem abandonados, devem ser aproveitados para pasto de grama ou capim" 47.

Enquanto houve cintas de mata nas fazendas, sua contigüidade em relação às fileiras de café ajudou a resistência. Segundo Stein, "uma vez que os cafezais eram geralmente próximos à mata virgem, os escravos, trabalhando em grupos, pediam permissão para sair a fim de atender suas necessidades fisiológicas e então fugiam". Flávio Gomes examinou como grupos pequenos de escravos fugitivos se valiam da paisagem irregular do Vale do Paraiba para se acobertar e montar ranchos provisórios, muitas vezes nas manchas de floresta dentro de unidades cafeeiras em operação, a partir dos quais furtavam ocasionalmente porcos, galinhas, café e mantimentos. Os cafezais podiam se tornar lugares fatais para os próprios senhores: Oliveira Jr e Agostini encontraram casos em Bananal e Vassouras nos quais escravos se esconderam nas linhas de café, tocaiaram e mataram seus proprietários 48 .

A correlação social de forças no Vale era, todavia, profundamente assimétrica. A despeito de todas essas ações de resistência escrava, os métodos de gestão do trabalho e da paisagem agricola por lá empregados reafirmavam constantemente o poder senhorial. 0 esquema agronômico devastador adotado de forma consciente pelos proprietários das fazendas, que combinava expansão continuada das derrubadas, plantio alinhado vertical com grande afastamento entre as fileiras de arbustos, trabalho coletivo nas capinas e sistema de tarefas nas colheitas para contrabalançar a falta de mão-de-obra, prosseguiu até bem entrados os anos oitenta, já no contexto de crise terminal do escravismo brasileiro.

Em suas duas décadas finais, à medida que a escravaria envelhecia, as terras virgens escasseavam e a produtividade dos pés decrescia, a carga de trabalho aumentou de modo substancial para os escravos de roça. Laërne, agrônomo com vasta experiência de terreno em Java, ao visitar, entre os meses de setembro de 1883 e abril de 1884, as regiões cafeeiras das provincias do Rio de Janeiro, Minas Gerais e São Paulo, ficou espantando com o incrivel ritmo de destruição das matas, de depauperação dos solos nas zonas mais antigas e, sobretudo, com as taxas de exploração do trabalho. Laërne calculava que, entre doze a quinze anos, a perda de cobertura de solo com as chuvas, decorrente do plantio alinhado vertical nos morros de meia-laranja, era de 20 a 35 centímetros, ou seja, um terço da camada média de húmus existente após a derrubada e queima da mata virgem; não era por acaso, assim, que a produção e o valor de mercado dos arbustos despencavam após essa idade. Neste passo, ao cabo de três décadas a cobertura de solo desaparecia por inteiro 49 .

Com a alta dos preços do café na década de 1870, o plantio de novos cafezais se acelerou, mesmo em zonas antigas com disponibilidade menor de terras virgens e de trabalhadores. Antes, isto é, nas décadas de 1850 e 
50

LAËRNE, C.F.van Delden. Brazil and Java. Report on Coffee-Culture in America, Asia, and Africa. Londres-Haia: Martinus Nijhoff, 1885. p.290.

51

Ibidem, p. 304

52

SLENES, Robert W. Grandeza ou Decadência? 0 mercado de escravos e a economia cafeeira da Província do Rio de Janeiro, 1850-1888. in: NERO, Iraci del (org.). Brasil: história econômica e demográfica. São Paulo: IPE-USP, 1986, p.139-140.

53

A análise dessa comunidade foi realizada por GOMES, Flávio dos Santos. Histórias de quilombolas. Mocambos e comunidades de senzalas no Rio de Janeiro, século XIX. (Edição revista e ampliada) São Paulo: Companhia das Letras, 2006. p.34-52.

54

Ver, a respeito, SILVA, Eduardo. Barões e Escravidão. Três gerações de fazendeiros e a crise da estrutura escravista. Rio de Janeiro: Nova Fronteira, 1984. p.157, e RIBAS, Rogério de Oliveira. Tropeirismo e escravidão: um estudo das tropas de café das lavouras de Vassouras, 1840-1888. Dissertação de Mestrado em História. Curitiba: UFPR, 1989. p.187-193.
1860, a um escravo de roça no Vale do Paraiba se atribuía uma quantidade máxima de 4.500 a 5.000 pés; agora, "a paixão pela plantação [de café] tem sido tão violenta que, na maior parte dos distritos da zona do Rio, um escravo tem que cuidar de mais de 7000 pés" 50. Durante sua estadia, que ocorreu no período de entressafra, Laërne tomou notícia com os fazendeiros e administradores por ele entrevistados que um escravo seria capaz de apanhar, no pico da colheita, de oito a nove alqueires de café, ou seja, o triplo da tarefa anotada pelo padre Aguiar nos anos 1830 e entendida como a norma pelos escravos do comendador Venâncio, em seus reclamos de 1866 contra o feitor Manoel Duarte Simões ${ }^{51}$. 0 historiador Robert Slenes, ao citar o mesmo trecho de Laërne, avançou a hipótese de que, nas regiões do Vale com poucos recursos florestais, os fazendeiros que, nos anos setenta, não optaram pela migração para as fronteiras cafeeiras, adotaram a estratégia de "aumentar a velocidade com que consumiam suas terras e plantações" 52. Era exatamente isso o que estava se passando na fazenda Resgate em 1881: naquela manhã, Antonio Ignácio partira com o terno sob seu comando para a fazenda Três Barras, contígua à Resgate, pois as terras virgens desta última aptas à cafeicultura já haviam sido quase todas gastas.

A redução das reservas de mata também ajuda a entender por que, depois do levante e da fuga coletiva liderada por Manuel Congo (1838), que pretendia criar uma grande comunidade quilombola nas matas adjacentes ao municipio de Vassouras, praticamente desapareceram manifestações desta ordem nos municípios centrais da cafeicultura no Vale do Paraíba. É certo que variáveis como o contexto político imperial, o peso do aparato estatal e a sedimentação de comunidades cativas majoritariamente crioulas explicam melhor a mudança no perfil da resistência escrava na região, mas as condições geográficas cambiantes certamente jogaram seu papel. 0 "campo negro" do recôncavo da Guanabara, isto é, a comunidade de quilombolas das terras alagadiças de lguaçu com amplas ramificações entre escravos e vendeiros da região e ainda ativa nas décadas finais da escravidão 53 , não teria como se reproduzir na paisagem devastada de serra acima.

No Vale do Paraiba oitocentista, em duas palavras, as possibilidades materiais para os africanos em diáspora e seus descendentes recriarem saberes agrícolas trazidos da África eram muito restritas. Na paisagem da produção cafeeira, a agência africana, tal como a concebem Carney e Voeks, não teve papel de monta. A questão, no entanto, permanece aberta no que se refere às roças próprias dos escravos. Este é um campo de investigação bastante promissor, mas que foge aos propósitos imediatos deste artigo. De todo modo, com base no saber histórico atualmente disponível, pode-se avançar a hipótese de que tampouco aí houve aporte africano substantivo, no sentido assinalado pelos dois geógrafos. Há indícios consistentes de que os produtos de eleição dos escravos para o cultivo em suas roças eram aqueles passíveis de venda no mercado, vale dizer, o café e o milho, exatamente os dois principais artigos que os senhores os obrigavam a cultivar durante a semana ${ }^{54}$.

0 que se pode afirmar com acerto é que, nas roças próprias, a organização do trabalho seguia uma lógica bastante distinta da que era imposta pelos proprietários de segunda a sábado. Os especialistas documentaram à farta a oposição dos escravos ao esquema de trabalho em turmas sob vigilância estrita. Mais importante é o fato de os crescentes atos de insubordinação escrava verificados após a segunda metade da década de 1870 não raro se expressarem como um ataque direto ao sistema de gangs, estritamente 
Cf. STEIN, Stanley. Vassouras. Um municipio brasileiro do café, 1850-1900. (1a ed: 1957; trad. port.) Rio de Janeiro: Nova Fronteira, 1990. p.176; GOMES, Flávio dos Santos. Histórias de quilombolas. Mocambos e comunidades de senzalas no Rio de Janeiro, século XIX. (Edição revista e ampliada) São Paulo: Companhia das Letras, 2006. p.257; MACHAD0, Maria Helena P.T. Crime e escravidão. Trabalho, luta e resistência nas lavouras paulistas, 1830-1888. São Paulo: Brasiliense, 1987. p.62 passim.

56

Analisei essas representações em MARQUESE, Rafael de Bivar. A paisagem da cafeicultura na crise da escravidão: as pinturas de Nicolau Facchinetti e Georg Grimm. In: Revista do Instituto de Estudos Brasileiro, São Paulo, V.44, p.55-76, fevereiro de 2007

57

Cf. COSTA, Emilia Viotti da. Da Senzala à Colônia. (1a ed: 1966) São Paulo: Brasiliense, 1989, p.37. Ver também STEIN, Stanley. Op.Cit., p.253-65.

\section{8}

Cf. DEAN, Warren. A ferro e fogo. A história e a devastação da Mata Atlântica brasileira. (trad. port.) São Paulo: Companhia das Letras, 1996. p.130.

\section{9}

Cf. FRAG0SO, João Luis Ribeiro. Sistemas agrários em Paraíba do Sul (1850-1920). Dissertação de Mestrado. Rio de Janeiro: IFCH/UFRJ, 1983 p.109-55; STEIN, Stanley. Op.Cit., p.304-335.
Recebido para publicação em março de 2008

Aprovado em abril de 2008 articulado, na paisagem, ao plantio alinhado vertical ${ }^{55}$. Essas manifestações eram um claro sinal da crise da escravidão. Não por acaso, na construção de sua auto-imagem por meio das pinturas de fazendas que comissionaram nesses anos, os senhores do Vale do Paraiba demandaram dos artistas a representação dos elementos que afirmavam seu poder sobre os escravos na paisagem, isto é, o plantio alinhado vertical e o espaço carcerário da senzala em quadra, acoplada ao terreiro e à casa de vivenda senhorial56.

As soluções de administração da paisagem aqui analisadas entraram em colapso com o fim da escravidão, sendo, na verdade, parte decisiva de sua própria crise. Como ressaltou Emília Viotti da Costa, a dificuldade dos proprietários do Vale do Paraiba em atrair imigrantes para suas fazendas os levou, na década de 1880, a se apegar ainda mais ao trabalho escravo, e uma das razões centrais para tal incapacidade era exatamente a queda de produtividade de seus cafezais, o que equivale a dizer devastação ambiental causada pela derrubada constante de matas, pelo plantio alinhado vertical e pelo abandono de cafezais envelhecidos. Noutros termos, o que antes era condição para a expansão produtiva se tornou um limite ${ }^{57}$.

0 fim da escravidão trouxe, além da reconfiguração das relações de trabalho ocorrida com a quebra das turmas sob comando unificado, uma profunda alteração na paisagem agricola. Como vimos ao longo do artigo, o café, um arbusto africano trabalhado por africanos escravizados e seus descendentes, levara à construção do Vale do Paraiba como região histórica. $\mathrm{Na}$ última década do século XIX, à medida que fazendeiros e ex-escravos estabeleciam novos acordos nos sistemas de colonato e parceria, ganhava impeto um terceiro vetor de africanização da paisagem do Vale, presente desde que os primeiros cafezais foram abandonados ainda na primeira metade do século. 0 capim-gordura (ou capim-melado, Melinis multiflora) que invadiu as terras devastadas pela cafeicultura provinha justamente do continente africano ${ }^{58}$. Fragoso lembra que "as terras em capim precedem a pecuária", ou seja, a formação de pastos decorreu da devastação ambiental, não sendo conseqüência da introdução da nova atividade. A pecuária foi o caminho que os ex-senhores encontram para manter a integridade de suas propriedades e barrar a repartição de suas terras. Os novos proprietários, que adquiriram várias das unidades de ex-senhores falidos com a crise financeira da abolição, ampliaram a atividade pecuarista, alterando por completo o espaço das antigas fazendas ao adaptá-las às novas funções 59 .

Nas últimas três décadas, muitas dessas portentosas fazendas oitocentistas foram convertidas em espaços de deleite de endinheirados do eixo Rio-São Paulo, algumas das quais inscritas nos circuitos turísticos. Delas, restam quase que unicamente as casas de vivenda monumentais, sem a contrapartida de tudo o que Ihes dava sentido no século XIX: cafezais, terreiros, engenhos $e_{1}$ em especial, senzalas. Não obstante o apagamento da memória da escravidão, reiterado nas falas dos guias e de alguns dos atuais proprietários, as marcas do aporte de africanos e descendentes estão em todo lugar: nas paredes, nos muros de pedra de imensos terreiros não mais em operação, nos morros desnudos, nos capins dos pastos pobres. Marcas, enfim, que expressam a brutalidade das relações de poder que estiveram na base da formação do Estado nacional brasileiro. 